\title{
Smart solution to icing accretion problems
}

\begin{abstract}
The present article is an opinion which addresses the challenges of human activity in cold regions. This opinion is focused on the different approaches which can be used to tackle the specific problem of icing accretion of external structures such as power distribution systems, under the project entitled: Study on Atmospheric Icing on Structures in the High North. In this sense a description of the International cooperation between Chongqing University and UiT-The Arctic University of Norway, supported by The Norwegian Centre for International Cooperation in Education (SIU) is described and analyzed with a view to finding solutions to increase the reliability of system operations. Trust in the power distribution relies on knowledge and understanding of the icing accretion phenomena. This is achieved by different means such as theoretical, analytical or numerical approaches that will create the base for the development of automated solutions including robot alternatives.
\end{abstract}

Keywords: SIU, robot, automated solutions, power distribution reliability, ice accretion
Volume 3 Issue I - 2017

\author{
Geanette Polanco,' Jiang Xingliang ${ }^{2}$ \\ 'Industrial Technology Institute, Arctic University of Norway, \\ Norway \\ ${ }^{2}$ Department of Electrical Engineering, Chongqing University, \\ China
} Correspondence: Geanette Polanco, Industrial Technology
Institute,Arctic University of Norway, Norway,

Email Geanette.polanco@uit.no

Received: September 12, 2017 | Published: September 21, 2017

\section{Introduction}

Enabling of human activities in regions with extreme weather is closely connected to the use of electricity, so the assurance of a reliable service is a main goal to be fulfilled. Extreme conditions represent constant hazard for the desired functioning condition, mainly due to the presence of icing on external structures. The major effects of ice accretion on external structures such as power lines towers, the power lines and ceramics insulators are the mechanical and thermal stresses imposed by the amount of ice formed on the structure and its distribution, along with the presence of the induced corona effect. Both effects constitute a potential hazard for the good development of human activities. Amount and distribution on ice on the external structure are influenced by atmospheric conditions such as wind speed and direction, temperature and humidity and the geometrical characteristics of the structure. Actions orientated to provide a good electricity distribution system in remote locations required realistic information that is not always possible to obtain directly from the actual system. This situation highlights the fact that cold climate simulators are a key aspect in testing the performance of new technologies for application in cold climate conditions to ensure they fulfill specific functionalities under extreme icing conditions. Simulations can be performed by numerical or experimental means. New technology developments includes methods, procedures and new inventions that are closely related to the monitoring of the problem and the management of the information about the behavior of the system to enable appropriate actions in managing the system. To guarantee continuous development in this key area specialized education must be made available to support the sector. In this sense initiatives such as the Study on Atmospheric Icing on Structures in the High North, a project supported by SIU, becomes key to the globalization of new alternatives and new approaches that will lead to improved solutions, including the gathering of the information required for the development and operation of automated or robotic solutions.

The project: study on atmospheric icing on structures in the high north

The aim of this project is to establish long-term academics/ research cooperation between Chongqing University, China (CQU) and UiT-The Arctic University of Norway (UiT) on topics related to cold climate and atmospheric icing on structures. Such cooperation will contribute towards the strategic infrastructure development of the High North region. The main outcomes of this project will be the development of joint master-level course modules, joint academic research projects and knowledge enhancement focusing on cold climate and atmospheric icing effects on high voltage power installations and wind energy in the High North. Expansion of higher education study programs and research activities related to atmospheric ice accretion and cold climate effects on structures, mainly high voltage power installations and wind turbines, in both institutions is a step towards reaching a viable solution to operating under these conditions. Mobility of staff and student is promoted to enhance professional development and extend academic/research networks. In this way, the interdisciplinary work focused toward development of new solutions will be assured.

Extended interaction with industrial representatives to share information on the latest developments in this field will also help to address future demands and challenges of the energy/power industry in cold weather regions. When solutions involve the use of robotics elements, information about possible scenarios and knowledge of the interaction of the different elements is very important. The development of analytical/theoretical/numerical models or procedure to understand the icing phenomenon is therefore key aspects to increase information about robotic or automated elements. As specific examples of the inclusion of the In 2015 SIU in collaboration with Cold Tech RT3 initiated six summer internships on various issues related with atmospheric icing on structures and up gradation of cold room simulator at UiT. Covered issues were the understanding and evaluation of the performance of step motor and servo motor in cold climate conditions, 3D Modeling and Manufacturing of an ABS Prototype for testing it's Thermal Conductivity in Cold Climate Conditions, understanding and practicing icing numerical modeling techniques using CFD tools, evaluating image processing technique for detecting ice, and evaluating anti icing and de icing technique by using resistive foil. In the same way in 2017, 3 students from CQU are 
working in the calculating method of ice accretion on wind turbine, the recent development of your icing detection sensors and the possible joint research and testing on our newly built $300 \mathrm{~kW}$ wind turbine.

\section{Numerical simulation media}

Actual gathered data in any process represent the real behaviour of the system under the present (uncontrolled) conditions, for instance, the case of performance of ice accretion around power lines on extreme climate conditions. In a similar manner, experimental data represents the behaviour of the system under controlled conditions, for example the conditions inside a cold chamber. Data include environmental information (pressure, temperature, humidity and wind speed and direction) at the specified location and information on the specific studied phenomenon such atmospheric icing. ${ }^{1}$ Wind profiles are closely related with the terrain type and complexity of the topology. ${ }^{1,2}$ In the case of ice accretion on wire, relating to instrument performance, the data include ice load, ice type, register of real time appearance of the ice, tension and torsion of the wire elements, electrical variables like electrical current, resistance (when applied) and power loss. Icing data can also be collected from experimental facilities not only at outside locations but from cold chamber experiments designed to reproduce specific conditions. ${ }^{3}$ Numerical simulations can be used to determine the ice shape around the structure. Ice shape from simulation can be compared with experimental data. CFD techniques are already used by researchers in the area of cold climate. ${ }^{4}$

\section{Experimental simulation media}

Experimental facilities are very important to produce information that improves understanding of complex phenomena. In this sense, the two participating institutions in the SIU project both possess state of the art experimental facilities. The use of this type of facilities allows to study different phenomena on different structures under controlled environment, as for example the study of the effects of icing degree on ice growth characteristics on insulators ${ }^{5}$ or the study of ice accretion on circular cylinders. Chongqing University has an external experimental facility that contains a test section of $1 \mathrm{~km}$ of power transmission line, together with a facility to test ice accretion on different insulator configuration/geometry, with the capacity of having 4 individual configurations at the time all located in the Xuefeng Mountain.

Both CQU and UiT have cold chambers for internal experimentation under controlled parameters. CQU cold chamber can reach a temperature of $-25^{\circ} \mathrm{C}$ in an inside space of $7 \mathrm{~m}$ diameter and $11 \mathrm{~m}$ high, that can be used to simulate and see the influence of the size/ shape of the chamber in the internal flow pattern. This chamber has the capability of housing insulators as well as a section of energized power lines. UiT's cold chamber has temperature control from $-30^{\circ} \mathrm{C}$ to $+20^{\circ} \mathrm{C}$ and turbine speed of 0 to $4 \mathrm{~m} / \mathrm{s}$. In order to create different forms of atmospheric ice air and water will be sprayed from the nozzle which is Bete Fog Nozzle, AC 1603. The air and water mixture can be regulated to reach different conditions. The other sensors in the cold rooms are FLIR (Thermograph) Camera and Mobotix Camera. Figure 1 shows CQU's cold chamber meanwhile Figure 2 shows UiT's cold chamber. Analysis of modeling/simulation and experimental data leads to a deeper understanding of icing trends in terms of the time variable. Statistics manipulation is frequently required to identify connection between different variables or the incorporation of new parameters, as dimensionless relations are needed in order to clarify the physical mechanics involved in a process.

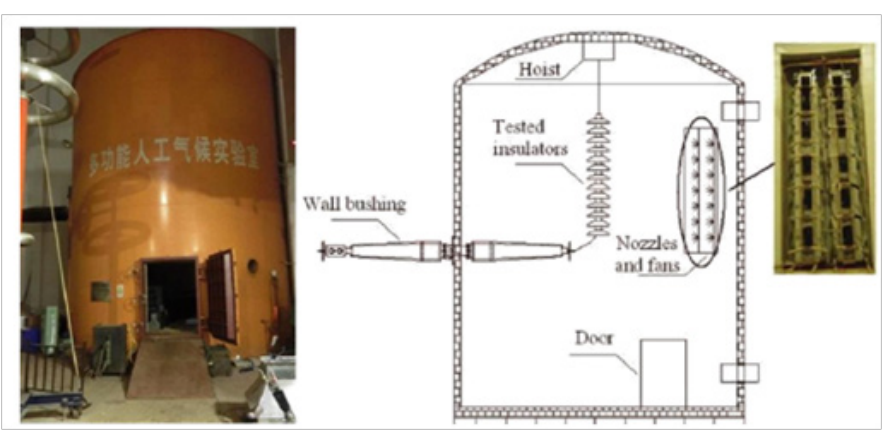

Figure I Cold chamber at Chongqing University, China.

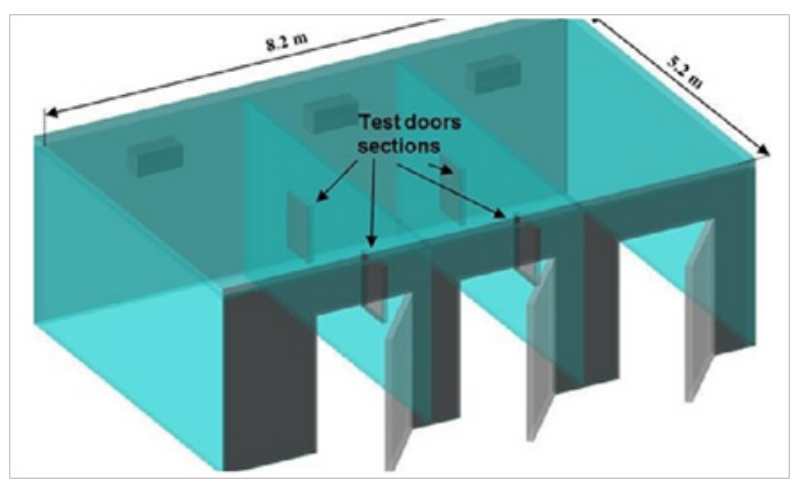

Figure 2 Cold chamber at UiT -The Arctic University of Norway.

\section{Smart solutions}

Robotics solution for excess of ice accumulated on structures has been realized for prototypes or patterns. The operation range for these elements required information about weather conditions as well as the icing phenomena. Technical aspects of the robots used for cold weather conditions must consider different scenarios that will limit their functioning range. Specially, when these worker robots are placed at areas where the weather becomes potentially dangerous for human beings. Application of artificial intelligence and robotics is also present in the new technology developed to tackle icing problems presented under cold climate scenarios. For instance the use of a robot for detecting the presence of ice on a surface as initial action to mitigate the related potential hazard. ${ }^{5}$ Even more complex concepts such as the polar robot have been developed to operate in extremely cold temperatures. ${ }^{6}$ A combination of low temperature and high wind velocities imposes extra constraints on the various elements of the robot that must be ruggedized to handle those conditions. In addition, extra requirements for movements are imposed by the possibility of being stuck in snow or ice formations.

A specific de-icing Robot for high voltage transmission lines was designed to be used as a control system to effectively remove ice on the transmission line, but it can also detect basic information, and comprehend the de-icing and line inspection. ${ }^{7}$ This robot includes a mobile mechanism, sensing system and control systems. Inspection procedures for power lines based on the fully automated power line inspection concept has also been developed, in order to increase reliability of the electric power supply and reduce maintenance costs. Power line robots are designed to examine line conditions feeding a maintenance making decisions system ${ }^{8-10}$ 


\section{Conclusion}

International academic/research cooperation initiatives facilitate the possibility of improving understanding of specific problems such as those encountered in electricity distribution in cold climate regions. As a direct result of that growth in understanding, new models, procedures or innovative inventions can result that address actual problems and challenges facing regional development. Robotics or automated solutions present an alternative method for monitoring working conditions, and minimizing the unwanted accumulated mass of ice on elements of power distribution systems. Nevertheless, more information about the complex icing accretion phenomena on structures is needed to continue to improve the range of operations of the new robotics. Theoretical, analytical and numerical approaches are important tools to improve knowledge in this topic area, each contributing to reaching the final goal of improved services, reliability and safety in difficult climatic conditions.

\section{Acknowledgments}

The work reported in this paper was funded by The Norwegian Centre for International Cooperation in Education (SIU) under the project no. HNP-2014/10023.

\section{Conflict of interest}

Author declares that there is none of the conflicts.

\section{References}

1. Thorsson P, Söderberg S, Bergström H. Modelling atmospheric icing: A comparison between icing calculated with measured meteorological data and NWP data. Cold Regions Science and Technology. 2015;119:124-131.

2. Rashid T, Mughal UN, Mustafa M, et al. A field study of atmospheric icing analysis in a complex terrain of the high north. International Journal of Ocean and Climate Systems. 2014.

3. Polanco G, Virk M. Numerical study of wind resource assessment of a complex terrain. The international journal of wind power. 2014.

4. Virk MS, Rashid T, Mughal UN, et al.Multi Sensor Atmospheric Icing Station Performance in Cold Climate-A Case Study. In Sensor Con. 2013.

5. Virk MS. Multiphase Numerical Study of Ice Accretion on Circular Cylinders in Duplex Configuration. Applied Mechanics and Materials. 2016;851:249-254.

6. Hu Q, Wang S, Yang H, et al. Effects of icing degree on ice growth characteristics and flashover performance of $220 \mathrm{kV}$ composite insulators. Cold Regions Science and Technology. 2016;128:47-56.

7. Koss HH, Gjelstrup H, Georgakis CT. Experimental study of ice accretion on circular cylinders at moderate low temperatures. Journal of Wind Engineering and Industrial Aerodynamics. 2012;104-106:540-546.

8. Anderson NPJFP. Ice mitigating robot. USA Patent. 2011.

9. Sukhatme G. The Path to Autonomous Robots. Springer; 2008.

10. Liu FHSZaSHJ. Design of Control System for the De-icing Robot on Transmission Line. Advances in Engineering Research. 2017;122:1-5. 